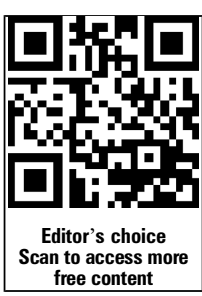

Scan to access mo free content

\title{
Prevalence of exercise-induced bronchoconstriction and exercise-induced laryngeal obstruction in a general adolescent population
}

\author{
Henrik Johansson, ${ }_{1}{ }^{*}$ Katarina Norlander ${ }_{1}{ }^{*}$ Lars Berglund ${ }_{1}^{3}$ Christer Janson, ${ }^{4}$ \\ Andrei Malinovschi, ${ }^{4}$ Lennart Nordvall, ${ }^{5}$ Leif Nordang, ${ }^{2}$ Margareta Emtner ${ }^{6}$
}

- Additional material is published online only. To view please visit the journal online (http://dx.doi.org/10.1136/ thoraxjnl-2014-205738).

${ }^{1}$ Department of Neuroscience/ Physiotherapy, Uppsala University, Uppsala, Sweden 2Surgical Sciences:

Otolaryngology and Head \& Neck Surgery, Uppsala University, Uppsala, Sweden ${ }^{3}$ Uppsala Clinical Research Center, Uppsala University, Uppsala, Sweden

${ }^{4}$ Medical Sciences, Uppsala University, Uppsala, Sweden ${ }^{5}$ Women's and Children's Health: Pediatrics, Uppsala University, Uppsala, Sweden ${ }^{6}$ Department of Neuroscience/ Physiotherapy, Uppsala University, Uppsala, Sweden

\section{Correspondence to} Henrik Johansson, Department of Neuroscience/Physiotherapy, Uppsala University, Box 593 BMC, Uppsala 751 24,

Sweden;

henrik.johansson@neuro.uu.se

*Henrik Johansson and Katarina Norlander have shared first authorship on this paper.

Received 14 May 2014 Revised 2 October 2014 Accepted 14 October 2014

Published Online First

7 November 2014

\section{CSLinked}

- http://dx.doi.org/10.1136/ thoraxjnl-2014-206096

\section{CrossMark}

$$
\begin{aligned}
& \text { To cite: Johansson } \mathrm{H} \text {, } \\
& \text { Norlander K, Berglund } \mathrm{L} \text {, } \\
& \text { et al. Thorax 2015;70: } \\
& \text { 57-63. }
\end{aligned}
$$

\section{ABSTRACT}

Background Exercise-induced respiratory symptoms are common among adolescents. Exercise is a known stimulus for transient narrowing of the airways, such as exercise-induced bronchoconstriction (EIB) and exerciseinduced laryngeal obstruction (EILO). Our aim was to investigate the prevalence of EIB and EILO in a general population of adolescents.

Methods In this cross-sectional study, a questionnaire on exercise-induced dyspnoea was sent to all adolescents born in 1997 and 1998 in Uppsala, Sweden $(n=3838)$. A random subsample of 146 adolescents

(99 with self-reported exercise-induced dyspnoea and 47 without this condition) underwent standardised treadmill exercise tests for EIB and EILO. The exercise test for EIB was performed while breathing dry air; a positive test was defined as a decrease of $\geq 10 \%$ in $F E V_{1}$ from baseline. ElLO was investigated using continuous laryngoscopy during exercise.

Results The estimated prevalence of EIB and EILO in the total population was $19.2 \%$ and $5.7 \%$, respectively. No gender differences were found. In adolescents with exercise-induced dyspnoea, 39.8\% had EIB, $6 \%$ had EILO and $4.8 \%$ had both conditions. In this group, significantly more boys than girls had neither EIB nor EILO (64.7\% vs $38.8 \% ; p=0.026)$. There were no significant differences in body mass index, lung function, diagnosed asthma or medication between the participants with exercise-induced dyspnoea who had or did not have a positive EIB or EILO test result.

Conclusions Both EIB and EILO are common causes of exercise-induced dyspnoea in adolescents. EILO is equally common among girls and boys and can coexist with EIB.

\section{INTRODUCTION}

Exercise-induced respiratory symptoms are common among adolescents. Exercise-induced dyspnoea was reported by $14 \%$ of Swedish adolescents ${ }^{1}$ and exercise-related wheezing was reported by $19 \%$ in the International Study of Asthma and Allergies. ${ }^{2}$ Although common, the reasons for exercise-induced respiratory symptoms have not been thoroughly investigated and are not well understood. Two possible causes of respiratory problems in conjunction with exercise are exerciseinduced bronchoconstriction (EIB) ${ }^{3} \quad 4$ and exercise-induced laryngeal obstruction (EILO). ${ }^{3} 56$

Several studies have investigated the prevalence of EIB, a transient narrowing of the lower airways

\section{Key messages}

What is the key question?

- What is the prevalence of exercise-induced bronchoconstriction (EIB) and exercise-induced laryngeal obstruction (EILO) in a general adolescent population assessed using standardised exercise tests?

What is the bottom line?

- The prevalence of EIB is $19.2 \%$ and the prevalence of EILO is $5.7 \%$ with no gender differences.

\section{Why read on?}

- This study shows that a large proportion of adolescents have EIB and EILO assessed using standardised methodology.

provoked by exercise. The prevalence in general populations of older children and adolescents varies between $7 \%$ and $16 \%{ }^{7-11}$ depending on the population under study, the diagnostic criteria and the environmental conditions. Although the studies used exercise tests for investigating EIB, not all of the studies used standardised tests and none of them used inhalation of dry air during the test, as recommended in the American Thoracic Society (ATS) clinical practice guidelines. ${ }^{4}$

EILO comprises a group of conditions that involves the vocal cords and the supraglottic structures in the larynx where the airflow in the larynx is obstructed during physical exertion. EILO is diagnosed by continuous laryngoscopy during exercise. $^{5} 12 \quad 13$ The only prospective study that has investigated the prevalence of EILO reported that it occurred in $7.5 \%$ of a cohort of subjects aged 14-24 years. ${ }^{14}$

Despite their different pathophysiological backgrounds, EIB and EILO can have similar symptomatology. For the correct diagnosis and treatment of adolescents with exercise-induced respiratory symptoms, it would be useful if clinicians were aware of the prevalence of EIB and EILO, whether there are any gender differences and the differences in clinical characteristics between those with and without these conditions. Previous studies investigating EIB with exercise tests were not performed according to recent guidelines, and only one prospective 
study has investigated the prevalence of EILO in a general population. Therefore, the aim of this study was to explore and assess the prevalence of EIB and EILO using standardised exercise tests in a general population of adolescents.

\section{METHODS}

\section{Participants and study design}

This cross-sectional study comprised two phases over a 2-year period: a screening phase and a clinical phase (figure 1).

\section{Screening phase}

During 2011 all 12-13-year-old adolescents in the city of Uppsala $(\mathrm{n}=3838)$ received a questionnaire on exercise-induced respiratory problems. ${ }^{1}$ The adolescents were also asked to report exercise-induced respiratory symptoms by answering the following question: 'Have you had any of the following symptoms more than once during or after physical exercise during the last 12 months; wheeze, chest tightness, cough, throat tightness, choking sensation, hoarseness or inspiratory stridor?'.

The response rate was $60.2 \%$. Based on the answer to the question 'Have you had an attack of shortness of breath that came following strenuous activity at any time, in the last 12 months?', ${ }^{15}$ the 2309 responders ( $\mathrm{n}=1136$ girls) were divided into two groups. The adolescents who responded positively to the question were defined as having exercise-induced dyspnoea $(n=330)$, while those who responded negatively were defined as controls $(n=1979)$. There were more girls than boys in the group reporting exercise-induced dyspnoea $(58 \%$ vs $42 \%$, respectively; $\mathrm{p}<0.001$ ).

\section{Clinical phase}

After stratifying for gender according to the results of the screening phase (female:male ratio 3:2), the adolescents with exercise-induced dyspnoea and the controls were randomly sequenced using computer randomisation. A total of 199 adolescents with exercise-induced dyspnoea and 123 controls were randomly selected and invited to participate in the study. The first 103 adolescents with exercise-induced dyspnoea and the first 47 healthy controls who agreed to participate were recruited for the clinical phase of the study which took place between March 2012 and June 2013. The exclusion criteria were pulmonary disease apart from asthma, cardiac co-morbidity or a functional disability that resulted in inability to perform exercise tests.

\section{Pre-test visit}

Age, sex, height and weight were recorded and body mass index (BMI) $\left(\mathrm{kg} / \mathrm{m}^{2}\right)$ was calculated. The use of inhaled corticosteroids, $\beta 2$-agonists and leukotriene receptor antagonists during the last 3 months was recorded. The participants were instructed on how to prepare for the two exercise tests, which were conducted on separate days.

\section{EIB test}

The EIB test was performed on average a median (IQR) of $12(6-19)$ days after the pre-test visit. The investigator (HJ) who collected the data was blinded to whether the participants belonged to the exercise-induced dyspnoea group or the control group.

Participants were instructed to cease short-acting $\beta 2$-agonists $8 \mathrm{~h}$ before the test, long-acting $\beta 2$-agonists $24 \mathrm{~h}$ before the test and leukotriene receptor antagonists $72 \mathrm{~h}$ before the test. They were also instructed not to use inhaled steroids on the day of the test and to avoid vigorous exercise, heavy meals, caffeinecontaining food or beverages and nicotine for $4 \mathrm{~h}$ before the test.

Baseline spirometry was performed according to ATS/ European Respiratory Society (ERS) guidelines ${ }^{16}$ and the prechallenge forced expiratory volume in $1 \mathrm{~s}\left(\mathrm{FEV}_{1}\right)$ was documented as the best $\mathrm{FEV}_{1}$ of three measurements (CardioPerfect dynamic spirometry; Welch Allyn, Höganäs, Sweden). During the standardised 6 min treadmill exercise test (Marquette Series 2000 Treadmill; GE, Waukesha, Wisconsin, USA), the subject wore a nose clip and breathed through a tube (Aiolos Asthmatest; Aiolos Medical, Karlstad, Sweden) connected to a central gas container with dry air $\left(\mathrm{H}_{2} \mathrm{O}<5 \mathrm{mg} / \mathrm{L}, 18-22^{\circ} \mathrm{C}\right)$. Heart rate was continuously monitored using a heart monitor (CASE Exercise Testing System; GE Medical Systems, Milwaukee, Wisconsin, USA). The end-point was to increase cardiac frequency to $90 \%$ of the predicted maximum ((208 $-(0.7 \times$ age $)) \times 0.9))^{17}$ within the first $1.5 \mathrm{~min}$ and maintain this level throughout the 6 min test by adjusting the treadmill speed and slope. $\mathrm{FEV}_{1}$ was measured 5, 10, 15 and $30 \mathrm{~min}$ after the test. The best $\mathrm{FEV}_{1}$ value of two measurements at each time point was documented. EIB was defined as a decrease of $\geq 10 \%$ in $\mathrm{FEV}_{1}$ from baseline. ${ }^{4}$

\section{Continuous laryngoscopy exercise test}

The continuous laryngoscopy exercise (CLE) test was performed a median (IQR) of 38 (22-66) days after the EIB test. The investigator $(\mathrm{KN})$ was blinded to whether the participants belonged to the exercise-induced dyspnoea group or the control group as well as to the EIB test result.

Participants were informed that there were no restrictions regarding asthma medication, that is, those who usually took asthma medication before physical exercise should also do so before the CLE test. Participants were instructed to avoid vigorous exercise on the day of the test and heavy meals for $4 \mathrm{~h}$ before the test.

The CLE test was performed according to the method described by Heimdal et $a l^{12}$ with minor modifications. Before the test, naphazoline-lidocaine was sprayed twice into each nostril to achieve local anaesthesia and dilatation. The participant warmed up on the treadmill at $10 \mathrm{~km} / \mathrm{h}$ for $2 \mathrm{~min}$ (Master Fitness T590; Master Fitness, Guangzhou, China). The treadmill was stopped and a fibre optic laryngoscope (Olympus ENF-P3; Olympus, Southend-on-Sea, UK) was inserted in one nostril. The tip of the laryngoscope was placed just above the epiglottis providing a detailed view of the larynx. The laryngoscope was fastened in a specially designed helmet so that it stayed in position, and was connected to a camera (Ubicam; Sopro Imaging, La Ciotat, France). The participant was equipped with a heart rate monitor consisting of a chest strap and wrist watch (T31; Polar, Oulu, Finland).

The participant started running at a speed of $9 \mathrm{~km} / \mathrm{h}$ with no inclination, and the speed was increased by $1 \mathrm{~km} / \mathrm{h}$ every minute until it reached $13 \mathrm{~km} / \mathrm{h}$. Thereafter, the inclination was increased by $2 \%$ every minute. The participants were instructed to run until breathing problems forced them to stop, or, if no breathing problems occurred, until exhaustion. For the test to be considered successful, the heart rate had to reach $\geq 90 \%$ of predicted maximum. ${ }^{17}$ The larynx was filmed continuously during the test and the larynx findings were graded immediately after the test according to the criteria described by Maat et al. ${ }^{13}$ An obstruction grade of 2 or more at either the supraglottic or the glottic level, or both, was considered to be a positive response and was defined as EILO. ${ }^{13}$ 
Figure 1 Participants' inclusion and exclusion. ElB, exercise-induced bronchoconstriction; CLE, continuous laryngoscopy exercise test.

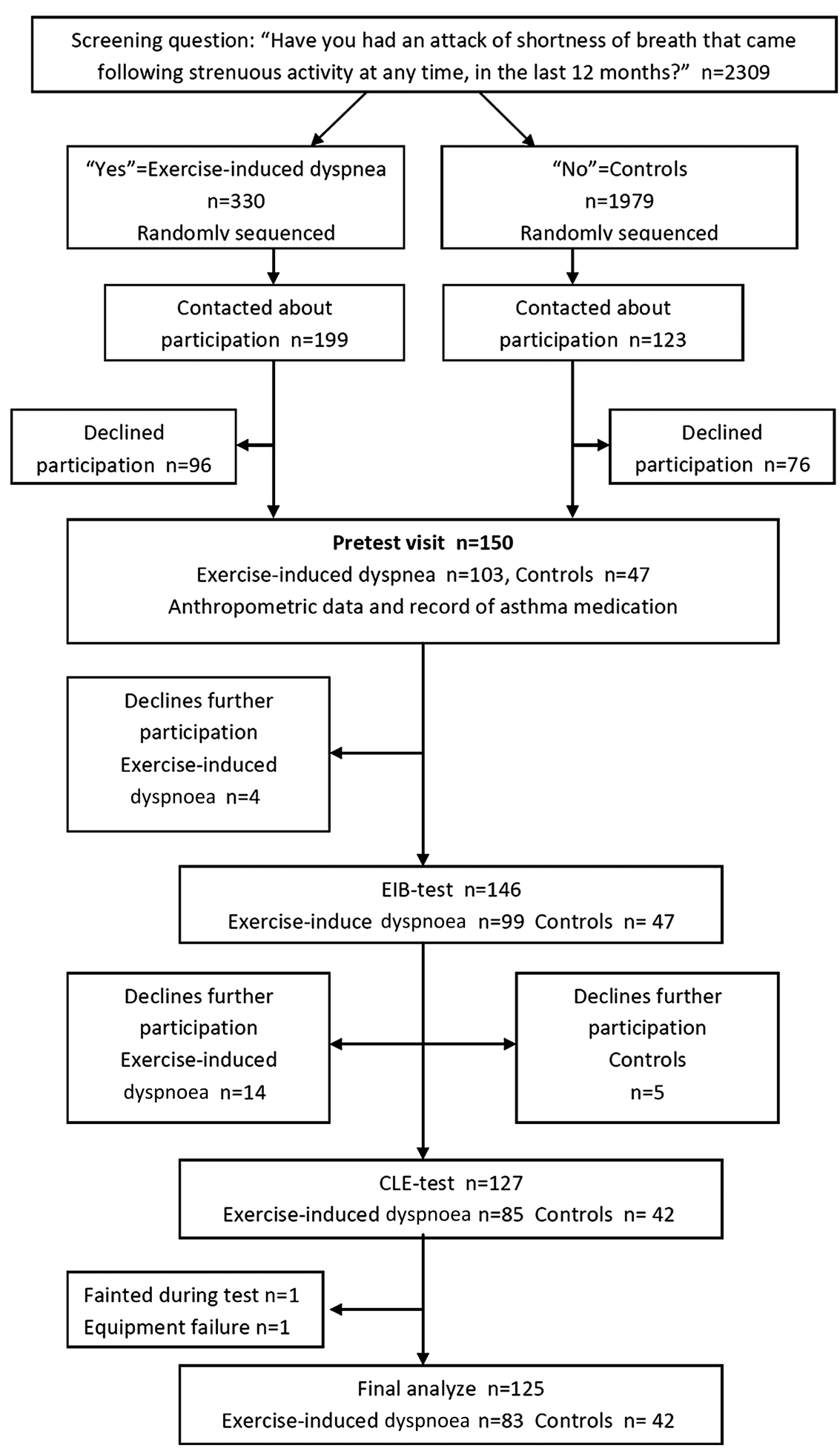

\section{Dropouts from the study}

Four subjects with exercise-induced dyspnoea declined participation in the exercise tests, leaving 146 subjects (99 with exercise-induced dyspnoea and 47 healthy controls) who performed the EIB test. For the CLE test, another 19 subjects (14 subjects from the group with exercise-induced dyspnoea) declined participation and two subjects were excluded due to fainting during the CLE test and equipment failure (figure 1).

\section{STATISTICAL ANALYSIS}

The data were analysed using Statistical Package for Social Science (SPSS) software, V.21 (SPSS, Chicago, Illinois, USA). Anthropometric data, lung function, asthma medication and exercise test results were summarised as the means, SDs and minimum and maximum for continuous variables, and as numbers and percentages for categorical variables. Age, BMI and $\mathrm{FEV}_{1}$ were compared between subject groups using unpaired Student's t tests. For all categorical variables, a cross- 
tabulation versus subject groups was performed and subject groups were compared using Fisher's exact test. The results were considered to be statistically significant at $\mathrm{p}<0.05$.

The EIB and EILO prevalence estimates were based on the assumptions that the population strata with and without exercise-induced dyspnoea differed. Assuming that there was no selection bias, the dyspnoea stratum with exercise-induced dyspnoea was calculated from the rate of exercise-induced dyspnoea among responders multiplied by the population size, and the stratum without exercise-induced dyspnoea was assumed to represent the rest of the population. The adolescents who underwent the EIB and CLE tests were assumed to be random samples from the two strata. The prevalence estimate and 95\% CI were calculated according to the theory for stratified samples. ${ }^{18}$

\section{RESULTS}

Of the 150 subjects who were referred for assessment, 103 had exercise-induced dyspnoea and 47 were controls. Group characteristics are presented in table 1. In the group with exercise-induced dyspnoea, more adolescents reported ever having been diagnosed with asthma by a physician and they had used more asthma medication compared to controls.

\section{Prevalence of EIB in the total population}

EIB was present in $42(42.4 \%)$ adolescents in the exercise-induced dyspnoea group and in seven (14.9\%) adolescents in the control group (table 1). The estimated prevalence of EIB in the population of 3838 adolescents was $19.2 \%$ (95\% CI 9.9\% to $28.4 \%$ ), $18.6 \%$ in girls and $19.7 \%$ in boys $(\mathrm{p}=0.91)$ (figure 2$)$.

\section{Prevalence of EILO in the total population}

EILO was present in nine $(10.8 \%)$ adolescents in the exercise-induced dyspnoea group and in two (4.8\%) adolescents in the control group (table 1). The estimated prevalence of EILO in the population was $5.7 \%$ (95\% CI $0.01 \%$ to $11.4 \%$ ) with no gender differences ( $p>0.99)$ (figure 2).

\section{Adolescents with exercise-induced dyspnoea without EIB or EILO}

Of the adolescents with exercise-induced dyspnoea, 49.4\% had neither EIB nor EILO (figure 3). Significantly more boys than

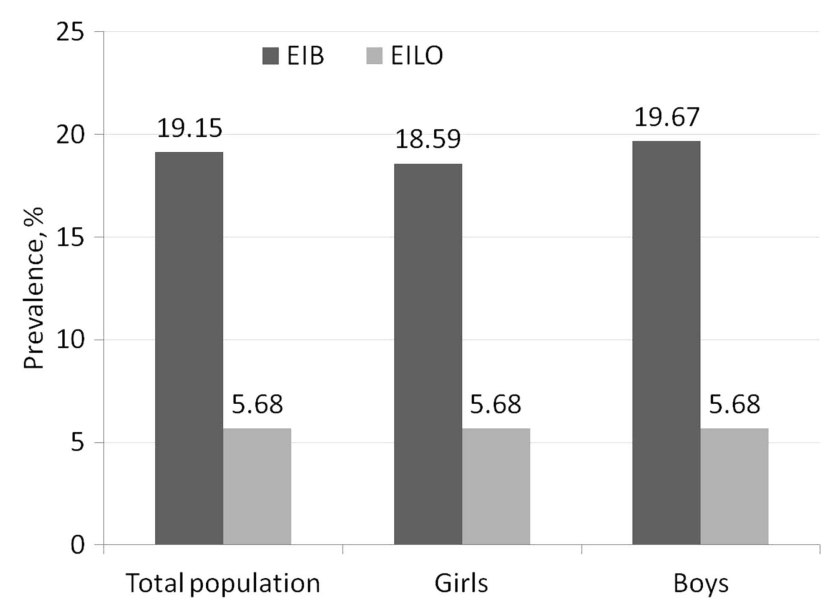

Figure 2 Prevalence (\%) of exercise-induced bronchoconstriction (EIB) and exercise-induced laryngeal obstruction (EILO) in the total population and in girls and boys.

girls did not have EIB or EILO (64.7\% vs $38.8 \%$; $\mathrm{p}=0.026)$ (table 2 and figure 4). There were no significant difference in BMI, lung function, ever asthma or medication between those with and without a positive EIB and/or EILO test (table 2). Regarding self-reported exercise induced symptoms there were no differences between participants with exercise-induced dyspnea that had or did not have EIB or EILO (see online supplementary table).

\section{Dropouts from the study}

The adolescents with exercise-induced dyspnoea who declined to participate in the clinical phase of the study $(n=93)$ did not differ from the group of participating adolescents with exercise-induced dyspnoea $(n=103)$ regarding age, gender or BMI; however, a larger proportion of participating adolescents reported ever asthma $(48 \%$ vs $32 \% ; \mathrm{p}=0.028)$. Similarly, a larger proportion of participating controls $(n=47)$ compared to controls who declined to participate $(n=76)$ reported ever asthma $(21 \%$ vs $4 \% ; \mathrm{p}=0.002)$; however, the groups did not differ regarding age, gender or BMI.

Table 1 Population and group characteristics

\begin{tabular}{|c|c|c|c|c|}
\hline & Total & Exercise-induced dyspnoea & Control & p Value \\
\hline Subjects, $n$ & 146 & 99 & 47 & \\
\hline Age (years), mean (min, max) & $14.2(13,15)$ & $14.2(13,15)$ & $14.2(13,15)$ & 0.66 \\
\hline Girls, n (\%) & $88(60.3)$ & $62(62.6)$ & $26(55.3)$ & 0.47 \\
\hline BMI, mean (SD) & $21.0(2.8)$ & $21.1(2.8)$ & $20.9(2.9)$ & 0.79 \\
\hline $\mathrm{FEV}_{1} \%$ predicted ${ }^{*}$, mean (SD) & $92.5(10.2)$ & $92.0(10.6)$ & $93.5(9.2)$ & 0.40 \\
\hline Ever asthmat, n (\%) & $43(29.5)$ & $41(39.8)$ & $2(4.3)$ & $<0.001$ \\
\hline Inhaled corticoid steroids $\ddagger$ n (\%) & $25(17.1)$ & $24(23.3)$ & $1(2.1)$ & $<0.001$ \\
\hline SABA $\ddagger, n(\%)$ & $29(19.7)$ & $26(25.2)$ & $3(6.4)$ & 0.004 \\
\hline LABA $\ddagger$, n (\%) & $1(0.7)$ & $1(1.0)$ & 0 & $>0.99$ \\
\hline LTRA $\neq, \mathrm{n}(\%)$ & $5(3.4)$ & $5(5.1)$ & 0 & 0.18 \\
\hline \multicolumn{5}{|c|}{ Exercise tests, positive/all tested, $n(\%)$} \\
\hline ElB test & 49/146 (33.6) & $42 / 99(42.4)$ & $7 / 47(14.9)$ & $<0.001$ \\
\hline CLE test & $11 / 125(8.8)$ & $9 / 83(10.8)$ & $2 / 42(4.8)$ & 0.33 \\
\hline
\end{tabular}

* Recorded before the exercise-induced bronchoconstriction test.

tSelf-reported, physician diagnosed.

¥Self-reported, any use in last 3 months.

BMI, body mass index $\left(\mathrm{kg} / \mathrm{m}^{2}\right)$; CLE, continuous laryngoscopy exercise test; EIB, exercise-induced bronchoconstriction; LABA, long-acting bronchodilator agent; LTRA, leukotriene receptor antagonist; SABA, short-acting bronchodilator agent. 
Adolescents with exercise-induced dyspnoea $(\mathrm{N}=83$ )

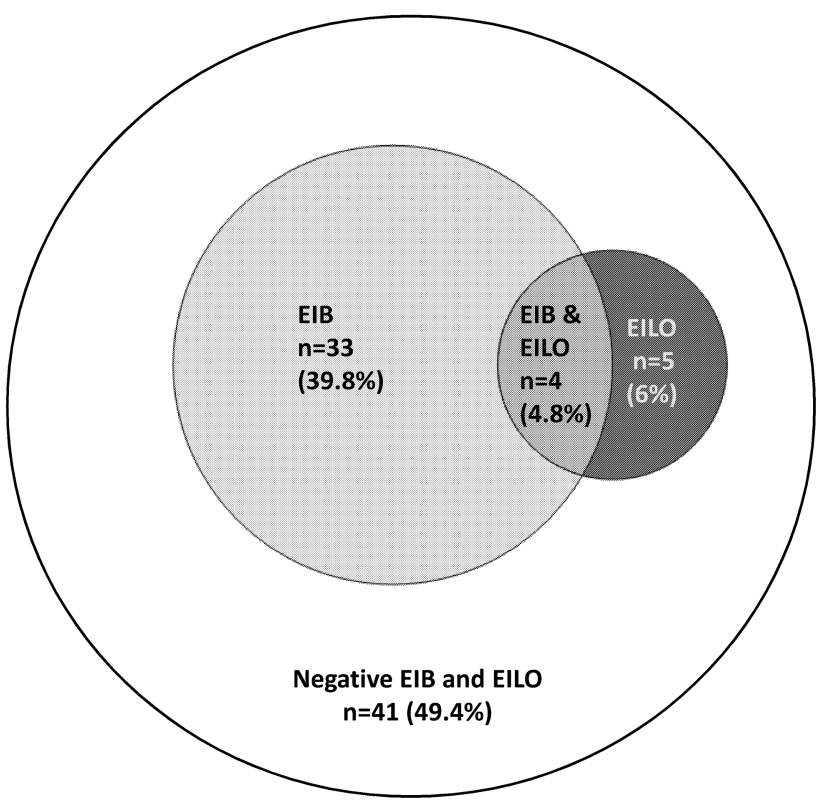

Figure 3 Exercise-induced bronchoconstriction(EIB) and exercise-induced laryngeal obstruction (EILO) in adolescents reporting exercise-induced dyspnoea.

\section{DISCUSSION}

The present cross-sectional study demonstrated that EIB and EILO, assessed using standardised exercise tests, are common in a general population of adolescents. The estimated prevalence of EIB was $19.2 \%$ and the estimated prevalence of EILO was $5.7 \%$, with no gender differences. In subjects with exercise-induced dyspnoea, EILO alone and EIB in combination with EILO were found to a similar extent. In approximately half of the subjects with exercise-induced dyspnoea, neither EIB nor EILO could be demonstrated and the unexplained self-reported exercise-induced dyspnoea was more common among boys than girls.

This prospective study from a general population sample is the first to present data regarding EIB, EILO and co-occurrence of both together. This study is also the first to investigate the prevalence of EIB, in a general population, using inhalation of dry air during the standardised exercise challenge test in accordance with recent clinical guidelines from the ATS. ${ }^{4}$

In the present study the estimated prevalence of EIB was $19.2 \%$, which is higher than previously reported. The prevalence of EIB among 10-12-year-old children in Algeria was $16.1 \%$ when the 6 min free-running test was used and EIB was defined as a decrease of $\geq 15 \%$ in peak expiratory flow rate. ${ }^{10}$ Using the same exercise protocol for investigating 1314-year-old adolescents, Busquets et $a l^{9}$ found a prevalence of $11 \%$, while De Baets et $a l^{7}$ found a prevalence of $7.4 \%$ among primary school children. Hallstrand et $a l^{8}$ found an EIB prevalence of $9.4 \%$ when studying 256 adolescents; they used the 6 min free-running test but defined EIB as a decrease in $\mathrm{FEV}_{1}$ of $\geq 10 \%$. Lødrup Carlsen et $a l^{19}$ reported an EIB prevalence of $8.6 \%$ (defined as a decrease in $\mathrm{FEV}_{1}$ of $\geq 10 \%$ ) when 616 children (mean age 10.9 years) were exercise tested in a laboratory setting. The fact that in the present study, unlike in other studies, the subjects breathed dry air with a nose clip in place during the exercise test might have increased the sensitivity of the test, thereby increasing the prevalence. It is also possible that differences in climate conditions may partly account for differences in the reported prevalence of EIB in different geographical areas. EILO was not uncommon in our population and its prevalence was estimated to be $5.7 \%$. The only previous prospective study investigating a general population (aged 1424 years; mean age, 18.6 years) found a prevalence of $7.6 \%{ }^{14}$ However, the authors of that study concluded that the result might have been influenced by the low number of participants assessed for EILO, as only $98(17.6 \%)$ of 556 invited participants underwent the CLE test.

We did not find any gender differences in the estimated prevalence of EIB. However, data from previous studies are inconsistent. De Baets $\mathrm{et}_{\mathrm{al}}^{7}$ found an EIB prevalence of $8.5 \%$ in girls and $6.4 \%$ in boys, while Busquets et $a l^{9}$ also reported a higher prevalence of EIB among girls (13\%) than boys (9\%). In contrast, other studies did not reveal any gender differences. ${ }^{10} 20$

We investigated 13-15-year-old adolescents and found that the estimated prevalence of EILO was similar (5.7\%) in girls and in boys. Christensen et al reported a higher prevalence of EILO in females (OR females/males 1.61), ${ }^{14}$ while several case reports on EILO and vocal cord dysfunction found the majority

Table 2 Characteristics of subjects with exercise-induced dyspnoea without EIB and EILO versus subjects with exercise-induced dyspnoea with EIB and/or EILO

\begin{tabular}{|c|c|c|c|}
\hline & Exercise-induced dyspnoea without EIB or EILO & Exercise-induced dyspnoea with EIB and/or EILO & p Value \\
\hline Subjects, n (\%) & $41(49.4)$ & $42(50.6)$ & \\
\hline Age (years), mean (min, max) & $14.29(13,15)$ & $14.24(13,15)$ & 0.67 \\
\hline Girls, n (\%) & $19(46.3)$ & $30(71.4)$ & 0.026 \\
\hline BMI, mean (SD) & $20.8(3.1)$ & $21.1(2.2)$ & 0.53 \\
\hline $\mathrm{FEV}_{1} \%$ predicted ${ }^{*}$, mean (SD) & $91.9(12.0)$ & $91.1(9.5)$ & 0.94 \\
\hline Ever asthmat, n (\%) & $16(39.0)$ & $19(45.2)$ & 0.66 \\
\hline Inhaled corticosteroids $\ddagger$, n (\%) & $7(17.1)$ & $12(28.6)$ & 0.30 \\
\hline SABA $¥, \mathrm{n}(\%)$ & $19(46.3)$ & $19(45.2)$ & $>0.99$ \\
\hline LABA $\ddagger$, n (\%) & $2(4.9)$ & 0 & 0.24 \\
\hline LTRA $\ddagger$, n (\%) & $2(4.9)$ & $3(7.1)$ & $>0.99$ \\
\hline
\end{tabular}

${ }^{*}$ Recorded before exercise-induced bronchoconstriction test.

tSelf-reported, physician diagnosed.

$\neq$ Self-reported, any use in last 3 months.

Regarding self-reported exercise-induced symptoms, there were no differences between participants with exercise-induced dyspnoea who did or did not have EIB or EILO regarding exercise wheeze, chest tightness, cough, throat tightness, choking sensation, hoarse voice or inspiratory stridor.

BMI, body mass index $\left(\mathrm{kg} / \mathrm{m}^{2}\right)$; EIB, exercise-induced bronchoconstriction; EILO, exercise-induced laryngeal obstruction; LABA, long-acting bronchodilator agent; LTRA, leukotriene receptor antagonist; SABA, short acting bronchodilator agent. 
Boys with exercise-induced dyspnea $\mathrm{N}=34$

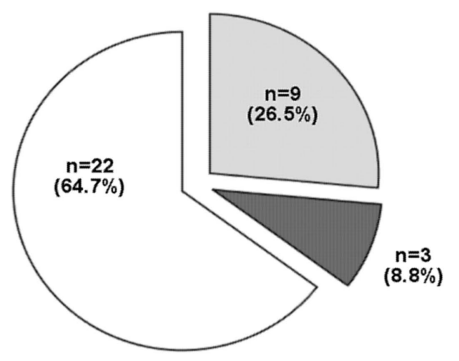

Girls with exercise-induced dyspnea N=49

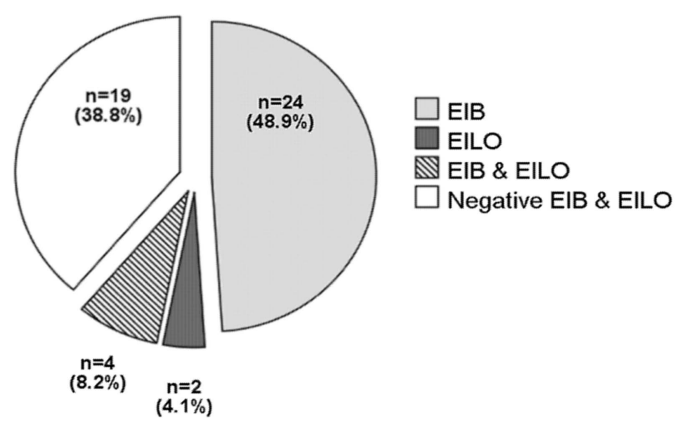

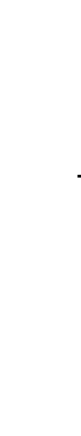

Figure 4 Exercise-induced bronchoconstriction (EIB) and exercise-induced laryngeal obstruction (EILO) in boys and girls reporting exercise-induced dyspnoea.

of patients were female. ${ }^{21-24}$ One plausible reason why more females had EILO in the study by Christensen et al could be because the population was older (14-24 years). By the age of 16-17 years, the male larynx has reached adult size, most likely reducing the problem for male individuals. In the present study, several males had gone through puberty, while other males were still prepubertal and had the narrow larynx of a child, which likely explains the lack of difference between genders.

Almost half of the participants with EILO also had EIB, so EILO and EIB might be related. This notion is partly supported by the findings that expiratory glottic constriction sometimes occurs during induced bronchial asthma. ${ }^{25}$ However, in our study none of the participants with both EILO and EIB had glottic closure. We therefore find it more likely that EILO is independent of EIB.

The fact that EIB and EILO are not mutually exclusive is important from a treatment perspective: if tested positive and successfully treated for EIB, an adolescent with both EIB and EILO may still experience breathing problems in conjunction with exercise. Thus, exercise testing for both EIB and EILO is a precondition for identifying subjects with both causes of transient airway narrowing.

A substantial proportion (49\%) of the participants reporting exercise-induced dyspnoea did not test positive for EIB or EILO. This finding is in agreement with previous studies. Abu-Hasan et $a l^{26}$ retrospectively reviewed exercise tests in 117 patients with exercise-induced dyspnoea (mean age, 14 years) and concluded that 52\% did not have cardiopulmonary abnormalities. One reason for exercise-induced dyspnoea is poor physical condition. ${ }^{27}$ In addition to being unfit, exercise-induced respiratory symptoms can have other causes such as restrictive abnormalities, primary hyperventilation, cardiac disease and congenital malformations. ${ }^{28} 29$ Further studies are needed in order to explain the underlying reason for exercise-induced dyspnoea in adolescents who have neither EIB nor EILO.

A larger proportion of the participating adolescents reported ever asthma compared to those who had declined participation. This result may have led to an overestimation of the prevalence estimates of EIB in the total population. Moreover, 25 participants in the clinical phase of the study did not complete both exercise tests; however, this group did not differ from the group completing both tests regarding baseline characteristics (data not shown). These dropouts are therefore unlikely to affect the prevalence estimate of EILO.

In conclusion, EIB is common among adolescents experiencing exercise-induced respiratory symptoms. EILO is also not uncommon in the general population and can be an important differential diagnosis in adolescents experiencing breathing problems in conjunction with exercise. EIB and EILO are not mutually exclusive and can co-exist; the diagnosis should be confirmed using standardised exercise tests.

Acknowledgements The authors thank participating adolescents and their guardians. The authors thank $\mathrm{H}$. Hedenström for contributing to the study design and P. Kalm-Stephens and K. Nisser for technical assistance.

Contributors $\mathrm{HJ}$ and $\mathrm{KN}$ contributed to study design, data collection, analysis and the first draft of the manuscript; LB contributed to study design, using prevalence estimates, statistical analysis and review of the manuscript; CJ, AM, LNordv and ME contributed to study design, analysis and review of the manuscript; LNorda contributed to study design, data collection, analysis and review of the manuscript; HJ, KN and ME had full access to all of the data in the study and were responsible for the integrity of the data and the accuracy of the data analysis.

Funding This study was sponsored by the Swedish Heart Lung Foundation (grant number 20110179), the Signhild Engqvist Foundation, the Bror Hjerpstedt Foundation and the Gillbergska Foundation.

Competing interests None.

Ethics approval The ethical review board in Uppsala, Sweden provided ethics approval for this study (Dnr 2011/413).

Provenance and peer review Not commissioned; externally peer reviewed.

\section{REFERENCES}

1 Johansson $\mathrm{H}$, Norlander $\mathrm{K}$, Hedenstrom $\mathrm{H}$, et al. Exercise-induced dyspnea is a problem among the general adolescent population. Respir Med 2014;108:852-8.

2 Pearce N, Aït-Khaled N, Beasley R, et al. Worldwide trends in the prevalence of asthma symptoms: phase III of the International Study of Asthma and Allergies in Childhood (ISAAC). Thorax 2007;62:758-66.

3 Weiler JM, Anderson SD, Randolph C, et al. Pathogenesis, prevalence, diagnosis, and management of exercise-induced bronchoconstriction: a practice parameter. Ann Allergy Asthma Immunol 2010;105(6 Suppl):S1-47.

4 Parsons JP, Hallstrand TS, Mastronarde JG, et al. An official American Thoracic Society clinical practice guideline: exercise-induced bronchoconstriction. Am J Respir Crit Care Med 2013;187:1016-27.

5 Røksund OD, Maat RC, Heimdal JH, et al. Exercise induced dyspnea in the young larynx as the bottleneck of the airways. Respir Med 2009;103:1911-18.

6 Nielsen EW, Hull JH, Backer V. High prevalence of exercise-induced laryngeal obstruction in athletes. Med Sci Sports Exerc 2013;45:2030-5.

7 De Baets F, Bodart E, Dramaix-Wilmet $M$, et al. Exercise-induced respiratory symptoms are poor predictors of bronchoconstriction. Pediatr Pulmonol 2005;39:301-5.

8 Hallstrand TS, Curtis JR, Koepsell TD, et al. Effectiveness of screening examinations to detect unrecognized exercise-induced bronchoconstriction. J Pediatr 2002;141:343-8

9 Busquets RM, Antó JM, Sunyer J, et al. Prevalence of asthma-related symptoms and bronchial responsiveness to exercise in children aged 13-14 yrs in Barcelona, Spain. Eur Respir J 1996;9:2094-8.

10 Benarab-Boucherit $Y$, Mehdioui $H$, Nedjar F, et al. Prevalence rate of exercise-induced bronchoconstriction in Annaba (Algeria) schoolchildren. J Asthma 2011:48:511-16 
11 Anthracopoulos MB, Fouzas S, Papadopoulos M, et al. Physical activity and exercise-induced bronchoconstriction in Greek schoolchildren. Pediatr Pulmonol 2012;47:1080-7.

12 Heimdal J, Roksund 0, Halvorsen T, et al. Continuous laryngoscopy exercise test: a method for visualizing laryngeal dysfunction during exercise. Laryngoscope 2006:116:52-7.

13 Maat R, Røksund O, Halvorsen T, et al. Audiovisual assessment of exercise-induced laryngeal obstruction: reliability and validity of observations. Eur Arch Otorhinolaryngol 2009;266:1929-36.

14 Christensen PM, Thomsen SF, Rasmussen N, et al. Exercise-induced laryngeal obstructions: prevalence and symptoms in the general public. Eur Arch Otorhinolaryngol 2011;268:1313-19.

15 The European Community Respiratory Health Survey II. Main Questionnaire. http:// www.ecrhs.org/Quests.htm [cited 10 March 2013].

16 Miller MR, Hankinson J, Brusasco V, et al. Standardisation of spirometry. Eur Respir J 2005;26:319-38.

17 Tanaka H, Monahan KD, Seals DR. Age-predicted maximal heart rate revisited. J Am Coll Cardiol 2001;37:153-6.

18 Murthy MN. Sampling: theory and methods. Calcutta: Statistical Publishing Society, 1967:253-4.

19 Lødrup Carlsen KC, Håland G, Devulapalli CS, et al. Asthma in every fifth child in Oslo, Norway: a 10-year follow up of a birth cohort study. Allergy 2006;61:454-60.
20 Bardagi S, Agudo A, Gonzalez CA, et al. Prevalence of exercise-induced airway narrowing in schoolchildren from a Mediterranean town. Am Rev Respir Dis 1993;147:1112-15.

21 Björnsdóttir US, Gudmundsson $\mathrm{K}$, Hjartarson $\mathrm{H}$, et al. Exercise-induced laryngochalasia: an imitator of exercise-induced bronchospasm. Ann Allergy Asthma Immunol 2000;85:387-91.

22 Sullivan MD, Heywood BM, Beukelman DR. A treatment for vocal cord dysfunction in female athletes: an outcome study. Laryngoscope 2001:111:1751-5.

23 Kenn K, Balkissoon R. Vocal cord dysfunction: what do we know? Eur Respir J 2011;37:194-200.

24 Fahey JT, Bryant NJ, Karas D, et al. Exercise-induced stridor due to abnormal movement of the arytenoid area: videoendoscopic diagnosis and characterization of the "at risk" group. Pediatr Pulmonol 2005;39:51-5.

25 Collett PW, Brancatisano T, Engel LA. Changes in the glottic aperture during bronchial asthma. Am Rev Respir Dis 1983;128:719-23.

26 Abu-Hasan M, Tannous B, Weinberger M. Exercise-induced dyspnea in children and adolescents: if not asthma then what? Ann Allergy Asthma Immunol 2005;94:366-71.

27 Seear M, Wensley $D$, West N. How accurate is the diagnosis of exercise induced asthma among Vancouver schoolchildren? Arch Dis Child 2005;90:898-902.

28 Weiss P, Rundell KW. Imitators of exercise-induced bronchoconstriction. Allergy Asthma Clin Immunol 2009;5:7.

29 Mahut B, Fuchs-Climent D, Plantier L, et al. Cross-sectional assessment of exertional dyspnea in otherwise healthy children. Pediatr Pulmonol 2014;49:772-81. 